\title{
Facial Burns: A One Year Audit at a Tertiary Hospital in Dar Es Salaam, Tanzania
}

\author{
Karpal Singh Sohal*, Elison NM Simon, Kalyanyama Boniphace M, Deoglas David K, Sira \\ Stanslaus Owibingire and Moshy Jeremiah Robert
}

Department of Oral and Maxillofacial Surgery, Muhimbili University of Health and Allied Sciences, Dar es Salaam, Tanzania

\begin{abstract}
Background: Facial burn injuries have plagued mankind since time immemorial and till the present day, they remain among the major public health problems. Since the face carries the identity of an individual, it is the most psychologically significant area of the body. Therefore, any disfigurement to the face such as that caused by burns has potential psychosocial consequences to the victim. The present study aimed at determining the etiology, pattern of occurrence and management of facial burns among patients attended at Muhimbili National Hospital, Dar es Salaam Tanzania.

Material and Methods: This was a one-year prospective study of all consecutive patients with facial burns who attended treatment at the Muhimbili National Hospital (MNH). The variables examined included socio-demographic characteristics, etiology, clinical features and management of facial burns. The data were analyzed using SPSS software for windows version 23 (IBM Corporation Chicago, IL, USA). Fisher's t-test was used and associations were considered significant when $\mathrm{p}<0.05$.
\end{abstract}

Results: A total of 112 patients with body burn injuries were attended during the period of this study where by $29.5 \%$ of the patients had burn injuries to the facial region. The male to female ratio was 2:1 and patient's age ranged from 17 to 70 years, with a mean age of 30.6 (SD 12.3) years. The etiological factors included open fire that affected (78.8\%) of the patients followed by scalding $(12.1 \%)$ and electricity $(9.1 \%)$. Majority $(81.8 \%)$ of the burn injuries were accidental in nature. The most frequently burnt facial aesthetic zones were the zygomatic region followed by the orbits. More than $80 \%$ of the participants had complications where by hypo-pigmentation was the commonest $(51 \%)$ complication of burn injuries encountered.

Conclusion: Facial burns affected males twice more than females. Open fire was the most common etiological factor and the zygoma was the most frequently affected facial esthetic zone. Majority of the patients had complications due to burn injury, of which the facial skin hypo-pigmentation was the commonest followed by death.

\section{Keywords}

Burn injuries, Facial, Fire

\section{Introduction}

Burn injuries have been defined as skin and tissue damage caused by fire, scald, electricity, chemical, or radiation [1]. These injuries are considered to be among the major sources of mortality and morbidity worldwide [2,3]. Compared to other injuries, burns have a significant impact on the psychosocial and physical well being of the patients $[4,5]$. In addition to that, they put financial stain to both the patients and their families because of long hospitalization and rehabilitation, and costly wound and scar treatment [4-6].

Though burn injury commonly affects the trunk region of the body [3], any part of the body is vulnerable including the face. The prevalence of facial burn ranges from 27 to $60 \%$, depending on prevailing socio-economic, cultural and environmental factors, and the definition of what constitutes facial burns [7]. Facial burns typically involve multiple facial aesthetic subunits and rarely occur in isolation [8].

The face, which carries the identity of an individual and constitutes the first contact point in various human interactions, is the most psychologically significant area

*Corresponding author: Karpal Singh Sohal, Department of Oral and Maxillofacial Surgery, Muhimbili University of Health and Allied Sciences, Dar es Salaam, Tanzania

Accepted: August 07, 2021

Published online: August 09, 2021

Citation: Sohal KS, Simon ENM, Boniphace KM, et al. (2021) Facial Burns: A One Year Audit at a Tertiary Hospital in Dar Es Salaam, Tanzania. Archives Oral Maxillofac Surg 4(2):137-142 
of the body $[7,9]$. Therefore, any disfigurement to the face has been found to have numerous potential psychosocial consequences for patients $[7,9,10]$. Despite this, few reports provide detailed comparable information regarding the circumstances and patterns of facial burn injuries in Tanzania. Epidemiological data on facial burns can provide vital information for developing prevention strategies, therefore reducing their frequency of occurrence and the economic demands on the health care system [11].

Considering the paucity of studies on facial burns, the present study was undertaken to determine the pattern of occurrence, etiology, clinical characteristics and management of facial burns among patients attended at Muhimbili National Hospital, Tanzania.

\section{Material and Methods}

This was a prospective hospital-based study of all consecutive patients who had sustained burn injuries and attended treatment at the Muhimbili National Hospital (MNH) between November 2017 and October 2018. A convenient sampling technique was used to recruit participants in this study. The inclusion criterion into the study was all patients with facial burns, aged 18 years and above who attended treatment at $\mathrm{MNH}$ within one-week post-injury. Those patients with facial burns who did not consent to participate were excluded from the study. Refusal to be included in the study or withdraw from the study did not in any way affect the patient's right to receive standard treatment.

All patients who consented to participate were included in the study and underwent an interview using a structured questionnaire. The questionnaire was assessed by a panel of experts in the field of oral and maxillofacial surgery in the hospital and was pretested before using it for the study. The obtained information in the study included socio demographic characteristics of the patients, causes of burn injury, and prior management before coming to $\mathrm{MNH}$. This was then followed by a thorough clinical examination. Facial burns were grouped according to the MCFONTZL system developed by Lee, et al. [12] with slight modifications where we considered it to be appropriate. In general, burns were classified with respect to their depth, according to involvement of the constituent layers of the skin. First-degree burns: affect only the epidermis and the hair follicles. Second-degree burns: affect the whole epidermis and a portion of the dermis or destructs the entire dermis. Third-degree burns: affect all layers of the skin, and can reach subcutaneous and other deeper tissues such as muscles, tendons, bones, and the digestive and respiratory tracts [13].

Confidentiality was maintained and identification numbers instead of patient's names were used in the questionnaires and clinical examination forms. All patients were treated according to the accepted available guidelines.

For analysis, the age was dichotomized into $\leq 30$ years and > 30 years; the education level was grouped into at most primary (primary and no formal education) and at least secondary (secondary and tertiary), and income was classified as volatile (no formal employment, students, peasants, petty traders and self-employed) and stable income (civil servants, private company employee and business personnel). The Body Mass Index (BMI) was categorized into underweight $(<18.5$ $\left.\mathrm{kg} / \mathrm{m}^{2}\right)$, normal weight $\left(18.5-24.5 \mathrm{~kg} / \mathrm{m}^{2}\right.$ ) and overweight ( $\geq$ $24.5 \mathrm{~kg} / \mathrm{m}^{2}$ ). The total body surface area (TBS) that was burnt was dichotomized into $\leq 35 \%$ and $>35 \%$. Out of the $9 \%$ that the head region accounts for the TBS burnt the categories were $\leq 4 \%$ and $>4 \%$.

The Statistical Package for Social Sciences software (SPSS) for Windows (version 23, IBM Corporation Chicago, IL, USA) was used. Selected variables were represented as frequencies and percentages. Fisher's t-test was used and associations were considered significant when $p<0.05$. Uncontrolled logistic regression was used to analyze the relationship between the outcome of burn injuries and selected risk factors. The results were reported as odds ratio and $95 \%$ confidence interval.

Ethical approval for the study was granted by the Muhimbili University of Health and Allied Sciences (MUHAS) committee of research and publication and the Institutional Review board of $\mathrm{MNH}$.

\section{Results}

Among 112 patients who attended treatment at $\mathrm{MNH}$ with burn injuries during the study period, $33(29.5 \%)$ had burn injuries to the facial region. Males were $22(66.7 \%)$ with a male to female ratio of $2: 1$. The age of the patients ranged from 18 to 70 years, with a mean age of 30.6 (SD 12.3) years. Most 21 (63.6\%) patients were in the age group of 30 years or less. Slightly more than half $(57.6 \%)$ of the patients were residing in suburban areas while 8 (24.2\%) and 6 (18.2\%) patients resided in urban and rural areas respectively. Those with education level of secondary school and beyond were 14 (42.4\%).

Majority, 24 (72.7\%) patients sustained burn injuries while at home, $7(21.2 \%)$ patients at work place and $2(6.1 \%)$ patients while in the streets. More than half $(54.5 \%)$ of the burn injuries occurred between 10 am and $7 \mathrm{pm}$, while the rest occurred between $8 \mathrm{pm}$ and 9 am.

The most common aetiology of burn injury was open fire in $26(78.8 \%)$ patients followed by scalding in $4(12.1 \%)$ and electricity in $3(9.1 \%)$ patients. Cooking stoves were the cause of open fire in 15 (57.7\%) patients followed by mishandling of fuel in $7(21.2 \%)$ and miscellaneous causes in 4 (12.1\%) patients. Of all types of stoves used, gas stoves accounted for most $12(80 \%)$ cases of burn injuries. Of the 4 patients with scald injury, $3(75 \%)$ were due to hot water and the remaining one was due to hot cooking oil (Table 1).

Majority, 27 (81.8\%) patients sustained burn injuries accidentally followed by 3 (9.1\%) who were set alight (two due mob justice, and the other as an act of revenge. The remaining 3 (9.1\%) patients had varying reasons for their burns that included epileptic attack, confusion following cerebral malaria and the act of suicide.

All patients sought treatment on the day of injury. Almost all, 31 (93.9\%) patients reported to health facilities in their 
Citation: Sohal KS, Simon ENM, Boniphace KM, et al. (2021) Facial Burns: A One Year Audit at a Tertiary Hospital in Dar Es Salaam, Tanzania. Archives Oral Maxillofac Surg 4(2):137-142

Table 1: Distribution of patients according to socio-demographic characteristics and causes of burn injuries.

\begin{tabular}{|l|c|c|c|}
\hline \multirow{2}{*}{$\begin{array}{l}\text { Socio-demographic } \\
\text { characteristics }\end{array}$} & \multicolumn{3}{|c|}{ Causes of burn injury } \\
\hline Sex & Open Fire & Electric & Scald \\
\hline Male & $16(72.2 \%)$ & $3(13.6 \%)$ & $3(13.6 \%)$ \\
\hline Female & $10(90.9 \%)$ & - & $1(9.1 \%)$ \\
\hline Age groups & & & \\
\hline$\leq 30$ years & $17(81 \%)$ & $1(4.8 \%)$ & $3(14.2 \%)$ \\
\hline > 30 years & $9(75 \%)$ & $2(16.7 \%)$ & $1(8.3 \%)$ \\
\hline Level of Education & & & \\
\hline At most primary & $15(78.9 \%)$ & $1(5.3 \%)$ & $3(15.8 \%)$ \\
\hline At least secondary & $11(78.6 \%)$ & $2(14.3 \%)$ & $1(7.1 \%)$ \\
\hline Surrounding/Setting & & & \\
\hline Home & $21(87.5 \%)$ & - & $3(12.5 \%)$ \\
\hline Away from home & $5(55.6 \%)$ & $3(33.3 \%)$ & $1(11.1 \%)$ \\
\hline Income & & & \\
\hline Volatile & $20(87.0 \%)$ & $1(4.3 \%)$ & $2(8.7 \%)$ \\
\hline Stable & $6(60 \%)$ & $2(20 \%)$ & $2(20 \%)$ \\
\hline
\end{tabular}

vicinities before being referred to $\mathrm{MNH}$, and the remaining 2 (6.1\%) had been referred directly to $\mathrm{MNH}$.

On the initial examination of the patients, all patients had patent airways without any difficulty in breathing and had normal limits of blood pressure. Their body mass indices (BMI) ranged from 19 to $32.8 \mathrm{~kg} / \mathrm{m}^{2}$ and most 22 (66.7\%) patients were within the normal range.

All the patients who had facial burns had other sites of their bodies injured as well. The upper limbs were the most affected in $30(90.9 \%)$ patients followed by the chestabdominal region in $23(69.7 \%)$ patients. The lower limbs and backs were affected in $63.8 \%$ and $33.3 \%$ of patients respectively. The total surface area of the body burnt ranged from $4 \%$ to $85 \%$ (mean of $31.2 \pm 21.0$ ), and majority $20(60.6 \%$ ) patients had burns of $\leq 35 \%$ of total body surface area.

The facial aesthetic zones that were frequently burnt included the zygomatic region followed by the orbits, whereas the chin and the temporal regions were the least affected (Figure 1). About one-third, 10 (30.3\%) patients had sustained first-degree burns and the rest had second-degree burns. None of the patients had $3^{\text {rd }}$-degree burn to the facial region, the surface area of the head that was burnt ranged from $2 \%$ to $9 \%$, and slightly less than half $(48.5 \%)$ of the patients had $\leq$ $4 \%$ surface area burns.

None of the patients required surgical intervention for definitive management. Analgesics, antibiotics and IV fluids were prescribed to all the patients (Table 2). Wound healing was evident within one week of admission in all except one patient who developed local infection. On assessing the outcome after one month, 27 (81.8\%) patients had complications predominated by scar-less hypo-pigmentation in $10(31 \%)$ patients followed by $9(27 \%)$ patients who lost life. Other complications included hypo-pigmentation with scarring and only one patient developed scars and contractures (Figure 2). There was no specific factor that was significantly associated with the occurrence of these general complications ( $p>0.05$ ), except for the degree of burn (Table 3 ).
A statistically significant association ( $p=0.001$ ) between the percentage of total body surface area (TBS) burnt and death was noted. Patients who had more than $35 \%$ of their body surface area burnt had 30 -folds higher odds of succumbing to the injuries compared to those with less than $35 \%$ of burnt TBS (OR $=30.4,95 \% \mathrm{Cl} 3.05-300.35)$.

\section{Discussion}

Facial burn injuries have plagued mankind since time immemorial and till the present day, they remain among the major public health problems responsible for significant morbidity and mortality universally [14]. In this study, the incidence of facial burns among patients who sustained burn injuries was almost $30 \%$ and this points to the relative importance of these injuries in our setting.

In the present study, males were twice more affected than females, findings which were in agreement with reports from other studies $[7,14]$ but contrary to those from India $[4,15]$. The reason for the male preponderance could be

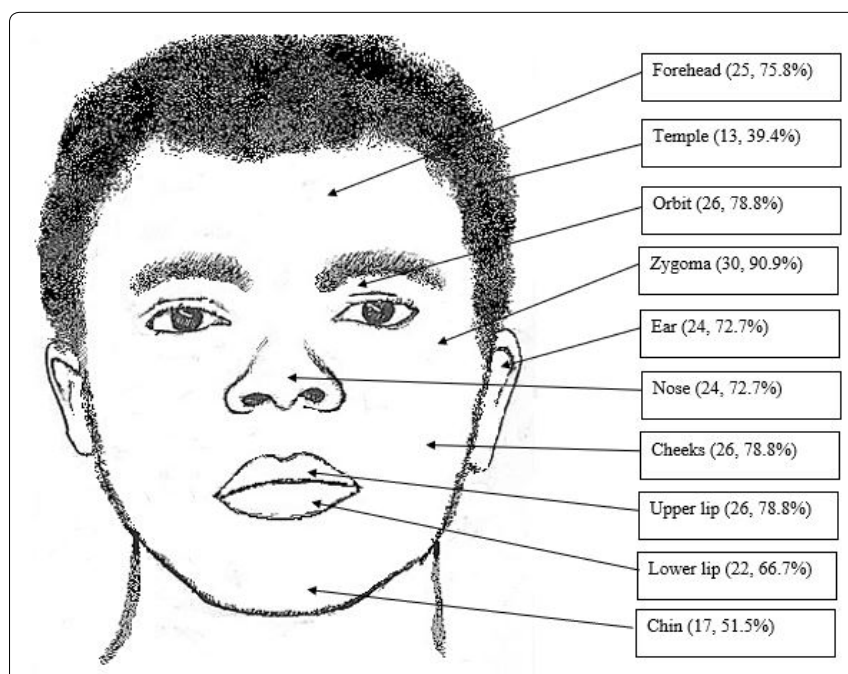

Figure 1: Distribution of patients according to burn injuries and facial esthetic sub-units.

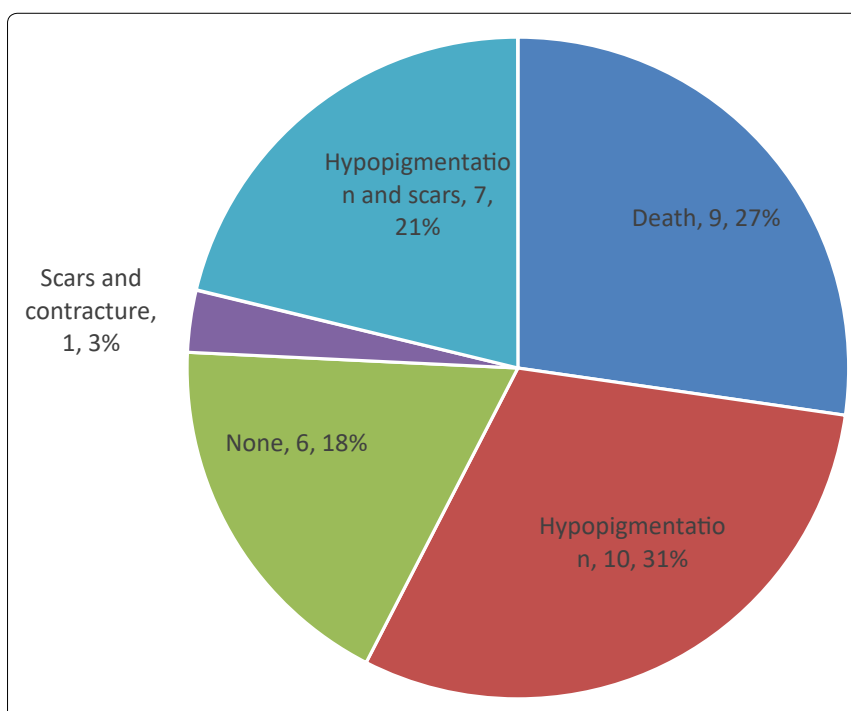

Figure 2: Percentage distribution of outcome of burn injuries. 
Citation: Sohal KS, Simon ENM, Boniphace KM, et al. (2021) Facial Burns: A One Year Audit at a Tertiary Hospital in Dar Es Salaam, Tanzania. Archives Oral Maxillofac Surg 4(2):137-142

Table 2: Management of patients according to the total body surface area that was burnt.

\begin{tabular}{|c|c|c|c|}
\hline \multirow{2}{*}{ Management } & \multicolumn{2}{|c|}{ Total burnt body surface area } & \multirow{2}{*}{ P-value } \\
\hline & $\leq 35 \%(n=20)$ & $>35 \%(n=13)$ & \\
\hline Tetanus toxoid & $15 \%$ & $15.4 \%$ & 1 \\
\hline IV fluids & $100 \%$ & $100 \%$ & - \\
\hline Blood transfusion & $10 \%$ & $38.5 \%$ & 0.084 \\
\hline Analgesics & $100 \%$ & $100 \%$ & - \\
\hline Antibiotics & $100 \%$ & $100 \%$ & - \\
\hline \multicolumn{4}{|l|}{ Wound dressing } \\
\hline Daily & $11.8 \%$ & $20 \%$ & \multirow{2}{*}{0.613} \\
\hline Every $2^{\text {nd }}$ day & $88.2 \%$ & $80 \%$ & \\
\hline
\end{tabular}

Table 3: The relation between selected variables and outcomes of the burn injury.

\begin{tabular}{|c|c|c|c|c|c|c|}
\hline \multirow[t]{2}{*}{ Variables of interest } & \multicolumn{3}{|c|}{$\begin{array}{l}\text { General complications within 1-month post- } \\
\text { burn: }\end{array}$} & \multicolumn{3}{|c|}{ Death } \\
\hline & No & Yes & p-value & No & Yes & p-value \\
\hline \multicolumn{7}{|l|}{ Sex } \\
\hline Male & $4(18.2 \%)$ & $18(81.8 \%)$ & \multirow{2}{*}{1} & $15(68.2 \%)$ & $7(31.8 \%)$ & \multirow{2}{*}{0.681} \\
\hline Female & $2(18.2 \%)$ & $9(81.8 \%)$ & & $9(81.8 \%)$ & $2(18.2 \%)$ & \\
\hline \multicolumn{7}{|l|}{ Age groups } \\
\hline$\leq 30$ years & $4(19 \%)$ & $17(81 \%)$ & \multirow{2}{*}{1} & $15(71.4 \%)$ & $6(28.6 \%)$ & \multirow{2}{*}{1} \\
\hline$>30$ years & $2(16.7 \%)$ & $10(83.3 \%)$ & & $9(75 \%)$ & $3(25 \%)$ & \\
\hline \multicolumn{7}{|l|}{ Body Mass Index } \\
\hline Normal & $2(9.1 \%)$ & $20(90.9 \%)$ & \multirow{2}{*}{0.146} & $15(68.2 \%)$ & $7(31.8 \%)$ & \multirow{2}{*}{0.681} \\
\hline Overweight & $4(36.4 \%)$ & $7(63.6 \%)$ & & $9(81.8 \%)$ & $2(18.2 \%)$ & \\
\hline \multicolumn{7}{|c|}{ Percentage of head surface burnt } \\
\hline$\leq 4 \%$ & $3(18.7 \%)$ & $13(81.3 \%)$ & \multirow{2}{*}{1} & $12(75 \%)$ & $4(25 \%)$ & \multirow{2}{*}{1} \\
\hline$>4 \%$ & $3(17.6 \%)$ & $14(82.4 \%)$ & & $12(70.6 \%)$ & $5(29.4 \%)$ & \\
\hline \multicolumn{7}{|c|}{ Percentage of body surface burnt } \\
\hline$\leq 35 \%$ & $6(30 \%)$ & $14(70 \%)$ & \multirow{2}{*}{0.06} & $19(95 \%)$ & $1(5 \%)$ & \multirow{2}{*}{0.001} \\
\hline$>35 \%$ & - & $13(100 \%)$ & & $5(38.5 \%)$ & $8(61.5 \%)$ & \\
\hline \multicolumn{7}{|l|}{ Degree of burn } \\
\hline First & $6(60 \%)$ & $4(40 \%)$ & \multirow{2}{*}{$<0.000$} & $8(80 \%)$ & $2(20 \%)$ & \multirow{2}{*}{0.686} \\
\hline Second & - & 23 (100\%) & & $16(69.6 \%)$ & $7(30.4 \%)$ & \\
\hline
\end{tabular}

explained by the behavior of this study population, which is characterized by a marked ability to explore the environment, excessive motor activity, and less carefulness [13].

Age is one of the important epidemiological determinants for burn injuries [15]. This study revealed that most of the adult patients who sustained facial burns were aged 30 years or below. A similar finding was reported in India [15], but contrary to findings from Bangladesh [16] where the elderly (> 65 years) were most affected. The differences between different countries may be attributed to socioeconomic, cultural, and environmental factors [7]. Since burns have a significant impact on the psychosocial, physical, and financial well being of the patients $[4,5]$, the facial burns in young adults affect their productive and reproductive contribution to the society.

A substantial number of patients sustained burn injuries at home, similar to findings from elsewhere $[3,4,15]$. This study found out that most of the burn injuries occurred during late morning and evening hours similar to what was reported in another study [17]. This could be due to the fact that cooking activities in the kitchen in most of the households take place during these hours. This was further augmented by the observation that most of the open fires were caused by stoves in particular the gas stoves. Of recent, gas stoves have been widely used in most parts of Tanzania, since they are affordable compared to electric stoves. Even though the gas stoves are simple to use, accidents occur frequently because the victims do not follow the instructions and do not observe the necessary precautions when using them as it has been reported in Pakistan [18]. During this study, some patients reported to have forgotten to turn off the valves after they had put off the flame. This led to continuous leakage of the gas, that later went into a blast of open fire as one returned to put on the flame again. Therefore, these findings call for the need to conduct preventive health education on the correct use and dangers of cooking gas at household and community levels.

All patients in this study sought treatment on the day of injury. This was contrary to findings from other studies $[5,17,19]$ which reported that only $80 \%$ of victims of burn injury tended to seek treatment in health facilities. The early reporting observed in this study could be attributed 
to the acute nature and extent of burn injuries. It has been documented elsewhere [17] that a significant relationship existed between the extent of burn sustained and treatmentseeking behavior. In cases where burn injuries were very minimum, patients would opt to self-medicate and they tended to seek care from health facilities when the injuries were extensive.

Typically, facial burns rarely occur in isolation and tend to involve multiple facial aesthetic subunits [8]. This was evident in the current study, where all the patients who sustained facial burns had other sites of body injured as well. The frontal parts of the upper extremity of the body were frequently affected followed by the lower extremities, similar to reports in the literature $[17,20,21]$. In the current study, all facial esthetics sub-units were nearly equally affected with burn injuries, however, the zygomatic region was the most affected zone. This could be attributed to the prominence of the zygoma that makes it the first contact point of the face during various injuries including the burns.

The facial burns in the present study were chiefly managed as per the existing protocol in the institute. Conservative treatment was opted for first-degree and second-degree burns. Therefore, the wounds were cleaned with normal saline followed by application of silver sulfadiazine ointment and application of petrolatum gauze. Other treatments given included analgesics, antibiotics and fluids. Antibiotics were important to prevent wound infection, which has been shown to have a strong association with mortality in some studies $[5,14,15]$.

In this study except for the degree of burn, no specific factors were significantly associated with the occurrence of general complications of facial burn. Similar findings were noted in a study from Nigeria [5]. Facial hypo-pigmentation was the most common complication encountered which could be explained by the degree of burn which patients had sustained. First degree and $2^{\text {nd }}$ degree burns usually affect the epidermis and a portion of or entire dermis, and not the deeper tissues [13]. As such, in first degree and second-degree superficial burns, healing is by primary intention, and the outcome is almost scar-less, however, there will be hypo-pigmentation of skin [22]. The mechanism of hypo-pigmentation in burn may be related to loss of melanocytes or damage to these cells causing a decrease in melanin synthesis [23]. Scars are said to be an inevitable consequence of burn injuries [24] and in this study almost $23 \%$ of the patients subsequently had scars. A scar is more likely to occur in second-degree deep burns since healing is by secondary intention [22].

Results of this study revealed a mortality rate of about $27 \%$ among patients who had sustained facial burns. Although there was no association noted between mortality and the extent of facial burns, a significant association between the percentages of total body surface area (TBS) burnt and death was noted. The deaths encountered in this study could be explained by the argument that facial burns may be associated with mortality due to possible smoke inhalation injuries. Moreover, the mortality rate for extensive burns was noted to be high, and the effect of inhalation injury might have been masked by the increased risk of mortality in the case of extensive burns. The possible causes of a high mortality rate in those with extensive burns could also be attributed to wound infection and hypovolemic shock [5].

The current study had some limitations which included small sample size and single-center study. Also, being a hospital-based study, it could miss other facial burns in the general population since some patients could seek care from elsewhere or else resort to self-medication. A multi-centric or possibly a community-based study with a larger sample size would give a better picture of the epidemiology of facial burn injury in the country. This study, however, provided valuable information in terms of causes and outcomes of facial burn injuries in our settings.

\section{Conclusion}

Facial burns were more common in males than females and the young adults were the most affected. A substantial number of patients sustained burn injuries while at home. The frequent etiology of burn injury was an open fire due to stoves, especially gas stoves, accounting for most of the open fire. The zygomatic region and the orbits were the most affected facial aesthetic zones. Nearly two-thirds of the patients had second-degree burns. Majority of the patients had complications due to burn injury, of which facial skin hypo-pigmentation was the commonest.

\section{References}

1. Gessesse FG, Yitayew YA (2020) Epidemiology of burn injury among children's attended felege hiwot referral hospital in Bahir dar town, Amhara regional state, Ethiopia, 2017. J Pediatrics and Neonatal Care 10: 21-27.

2. Oladele A O, Olekwu A, Babalola O, et al. (2018) Burn injury patterns and validation of the abbreviated burn severity index as a predictor of outcome in a southwestern Nigerian hospital. World J Surgery Surgical Res - General Surgery 1: 1070.

3. Oladele A O, Olabanji J K (2010) Burns in Nigeria: A review. Ann Burns Fire Disasters 23: 120-127.

4. Krishnamurthy V R, Ishwaraprasad G D, Sumana M, et al. (2018) Pattern of burn injury admissions at a teaching hospital of Karnataka, India: A three year retrospective study. Int Surgery Journal 5: 3930.

5. Fatusi O A, Fatusi A O, Olabanji J K, et al. (2006) Management outcome and associated factors in burn injuries with and without facial involvement in a Nigerian population. J Burn Care Res 27: 869-876.

6. Brusselaers N, Monstrey S, Vogelaers D, et al. (2010) Severe burn injury in Europe: A systematic review of the incidence, etiology, morbidity, and mortality. Crit Care 14: R188.

7. Zatriqi V, Arifi H, Zatriqi S, et al. (2013) Facial Burns - Our experience. Mater Sociomed 25: 26-27.

8. Bagby S K (2005) Acute management of facial burns. Oral Maxillofac Surg Clin North Am 17: 267-272.

9. Sohal K, Kalyanyama B, Simon E (2020) The pattern of assaultrelated oral and maxillofacial injuries among patients treated at the Muhimbili National Hospital, Dar es Salaam, Tanzania. Int Med 2: 119-124. 
10. Dhungana S, Shrestha M, Ghartimagar D, et al. (2015) Emergency imaging of head and cranio-facial injuries: Implementing NICE guidelines - a cross sectional analysis from western region of Nepal. Med Sci 3: 218-224.

11. Dhopte A, Tiwari V K, Patel P, et al. (2017) Epidemiology of pediatric burns and future prevention strategies-a study of 475 patients from a high-volume burn center in North India. Burns Trauma 5: 1-8.

12. Lee R H, Gamble W B, Robertson B, et al. (1999) The MCFONTZL classification system for soft-tissue injuries to the face. Plast Reconstr Surg 103: 1150-1157.

13. Magnani D M, Sassi F C, Andrade C R F de (2019) Orofacial rehabilitation in head and neck burns: A systematic review of the literature. Audiol, Commun Res 24: e2077-e2077.

14. Lal S, Shrivastava G, Singh S, et al. (2012) Mortality pattern of burn patients admitted in S. G. M. Hospital Rewa: A teaching institute of central India. J Scientific Society 39: 130-135.

15. Kumar M, Yasmin E, Kumar C, et al. (2018) Pattern of burn injury among patients admitted in a Tertiary Care Hospital of Jharkhand. International Journal of Community Medicine and Public Health 5: 3056.

16. He S, Alonge O, Agrawal P, et al. (2017) Epidemiology of burns in rural Bangladesh: An update. Int J Environ Res Public Health 14: 381.
17. Forjuoh S N (2006) Burns in low- and middle-income countries: A review of available literature on descriptive epidemiology, risk factors, treatment, and prevention. Burns 32: 529-537.

18. Ahmad M, Hussain S S, Malik S A (2007) Burns from a stove burst: Analysis of 34 cases. Ann Burns Fire Disasters 20: 173175.

19. Davé D R, Nagarjan N, Canner J K, et al. (2018) Rethinking burns for low \& middle-income countries: Differing patterns of burn epidemiology, care seeking behavior, and outcomes across four countries. Burns 44: 1228-1234.

20. Burton K R, Sharma V K, Harrop R, et al. (2009) A populationbased study of the epidemiology of acute adult burn injuries in the Calgary Health Region and factors associated with mortality and hospital length of stay from 1995 to 2004. Burns 35: 572-579.

21. Bataineh Z A, A I Quran T M, et al. (2018) Pattern of burn injury at north of Jordan. Int J Burns Trauma 8: 1-5.

22. Tiwari V K (2012) Burn wound: How it differs from other wounds. Indian J Plast Surg 45: 364-373.

23. Carney B C, McKesey J P, Rosenthal D S, et al. (2018) Treatment strategies for hypo pigmentation in the context of burn hypertrophic scars. Plast Reconstr Surg Glob Open 6: e1642.

24. Burd A (2010) Burns: Treatment and Outcomes. Semin Plast Surg 24: 262-280. 